Original Research Article

\title{
Antioxidant activity and effects of Kenyan Tea (Camellia sinensis) on the liver function and serum biochemistry in male Wistar rats
}

\author{
Gerald Otwabe Areba $^{1 *}$, Rashid Khalid ${ }^{2}$, Nyaga Samuel Nderitu ${ }^{3}$, Thuo Jesse Kevin ${ }^{3}$, \\ Moseti Kevin Okongo ${ }^{4}$, Karori Stephen Mbuthia ${ }^{5}$, Wachira Francis Nyamu ${ }^{6}$, \\ Ngure Raphael Muchangi ${ }^{7}$
}

\begin{abstract}
${ }^{1}$ Department of Veterinary
Pathology, Microbiology and

Parasitology, Egerton University,

Kenya

${ }^{2}$ Department of Ophthalmology,

University of Cologne, Germany

Kenya

${ }^{5}$ Department of Biochemistry and

Molecular Biology, Egerton

University, Kenya

${ }^{6}$ Division of Administration and

Human Resource Management,

South Eastern Kenya University,

Kenya

${ }^{7}$ Department of Veterinary

Pathology, Microbiology and

Parasitology, Egerton University,

Kenya

Received: 11 June 2018

Accepted: 03 July 2018

*Correspondence to:

Dr. Gerald Otwabe Areba,

Email: geraldareba2011@

gmail.com
\end{abstract}

${ }^{3}$ Department of Veterinary Anatomy

and Physiology, Egerton University,

${ }^{4}$ Department of Tea and Health, Tea Research Institute of Kenya, Kenya

Copyright: () the author(s), publisher and licensee Medip Academy. This is an open-access article distributed under the terms of the Creative Commons Attribution Non-Commercial License, which permits unrestricted noncommercial use, distribution, and reproduction in any medium, provided the original work is properly cited.

\begin{abstract}
Background: Tea is a beverage that is most widely consumed worldwide. Studies have shown that oral consumption of tea has health benefits however, there is paucity of data in Kenya detailing the biochemical effects of tea in the liver and elucidation of its mechanism of action.

Methods: The polyphenol composition and antioxidant capacity of tea were determined by HPLC and the Folins Ciocalteu spectrophotometric methods. Metal levels were determined using flame Atomic Absorption Spectrometer (AAS). Aqueous black and green tea extracts were administered to the rats at dosages of $400 \mathrm{mg} / \mathrm{kg}$ b.w.t. The effect of tea on total blood proteins, Albumin, ZHX1, TBARS, AST, ALP and ALT were determined by spectrophotometric methods. The body weight of each rat was also determined at one week interval. Results: Total Polyphenols (TP), Total Catechins (TC) and Antioxidant Activity (AA) between the black and green teas were significantly $(\mathrm{P}<0.05)$ different. Green tea had the highest levels of TP (19.70-26.12\%), TC (8.51\%-17.60\%) and AA (86.65\%-94.50\%). Tea did not have a significant ( $P>0.05)$ effect on TP, ALB, ALT, AST, ALP, MDA and ZHX1 in the test animals compared with the controls. This data indicates that green tea is rich in catechins while black tea being rich in Theaflavins (TFs) and Thearubigins (TRs). Both tea products possess essential and non-essential metals well within the maximum permissible concentrations. Conclusions: Findings from this study indicate both green and black tea aqueous extracts have polyphenols and high antioxidant activity. Administration of the aqueous tea extracts have no toxicological effect on the liver.
\end{abstract}

Keywords: Biochemical, Liver, Polyphenols, Tea

\section{INTRODUCTION}

Tea is a beverage that is most widely consumed worldwide. ${ }^{1,2}$ Tea has gained popularity due to its immense pharmacological, antioxidant and heavy metal chelating abilities. This beverage is now increasingly being employed in the management of hypertension, arteriosclerosis, hypoglycemia and hypocholesterolaemia. ${ }^{3}$ Additionally, it is hypothesized that the effectiveness of tea to manage most of the disease 
conditions is guided by its capability of reducing the levels of xenobiotics and the pro-oxidant effects.

Studies have also shown that oral consumption of tea reduces cancer risk. ${ }^{4,5}$ These beneficial effects are mainly attributed to teas anti-oxidant and chelating activities for metal ions. ${ }^{6}$ Furthermore, tea has been shown to be more potent than other antioxidants such as vitamins $\mathrm{C}$ and $\mathrm{E}$.? Despite such remarkable characteristics strengthened by research findings, there is still paucity of data linking its pharmacological abilities in the management of disease conditions linked to oxidative stress. It is in line with this that this study was set up to test the biochemical and clinical effects of tea infusions in the liver of rats since the liver plays a very critical role in metabolism and detoxification processes. This was accomplished by monitoring the levels of reduced glutathione (GSH), Thiobarburic acid reactive substances (TBARS), Zinc fingers and homeoboxes 1 (ZHX1), total proteins, alkaline phosphatase (ALP), Alanine aminotransferase (ALT) and Aspartate aminotransferase (AST).

\section{METHODS}

\section{Tea Samples}

Processed tea from cultivar TRFK 6/8 was used in this study. Black and green tea samples were processed from the cultivar at the Tea Research Institute (TRI) miniature factory using standard TRI optimized tea manufacturing procedures.

\section{Determination of catechins in tea infusions}

HPLC method was used to assay for the tea catechins as described by. ${ }^{8}$

\section{Determination of total polyphenols in the tea infusions}

The Folin-Ciocalteu phenol reagent method was used to determine total polyphenols as described by. ${ }^{9}$

\section{Analysis of total theaflavins content in the tea infusions}

Total theaflavins (TF) were determined as described by. ${ }^{10}$ Determination of Total Thearubigins in Tea Infusions. The total thearubigins was determined as described by the methods of Roberts and Smith. ${ }^{11}$

\section{Free radical scavenging activity of tea samples}

The stable 2,2-diphenyl-1-picrylhydrazyl radical (DPPH) was used for determination of free radical scavenging activity of the tea samples using a modified method of Brand-Williams. $^{12}$

\section{Determination of heavy metals in tea infusions}

Heavy metal determination in the tea samples was carried out as outlined by Ambadekar. ${ }^{13}$

\section{Animal study}

Adult male Wister rats weighing between $300-400 \mathrm{~g}$ were obtained from the University of Nairobi-Chiromo animal house. All experimental procedures and protocols involving experimental animals were reviewed and approved for adherence to ethical standards by the Institutional Animal Care and Use Committee (IACUC) of the Institute of Primate Research (IPR). The rats were maintained in standard rat cages on a 12-hour light-dark schedule at a temperature of $23^{\circ} \mathrm{C}$ and provided ad libitum access to standard rat cubes (Unga feeds Ltd, Kenya) and drinking water. The rats were acclimatized for 2 weeks before the start of the experiment.

\section{Experimental design}

The rats were randomly divided into three distinct groups. The tea infusions were given orally by gavage at a dosage of $400 \mathrm{mg} / \mathrm{kg}$ and for 52 days. After lapse of the experimental period, carbon dioxide was used to euthanize the animals after which blood was drawn from the heart by cardiac puncture using vacutainer needles. Liver tissues and a volume of $5 \mathrm{ml}$ blood were collected from each rat. These samples rats were used to investigate the biochemical and clinical effects of tea.

\section{Determination of body weight}

The body weight of each rat was also determined at oneweek interval using the analytical electronic balance (Mettler PM34, Doltarange®).

\section{Tissue preparation}

Snap frozen whole organs were homogenized on ice cubes $\left(4^{\circ} \mathrm{C}\right)$ in a solution containing $0.5 \mathrm{ml}$ of $0.25 \mathrm{M}$ sucrose, $5 \mathrm{mM}$ Hepes-Tris, $\mathrm{pH} 7.4$ with protease inhibitor cocktail to a final concentration of $10 \%(\mathrm{w} / \mathrm{v})$. The homogenates were then aliquoted in triplicates into $1.5 \mathrm{ml}$ cryovials to avoid repeated freeze thaw process and then stored at $80^{\circ} \mathrm{C}$ until analysis.

\section{Determination of glutathione}

Glutathione assay was performed as described by Rahman et al, with modifications from Rashid et al. ${ }^{14,15}$

\section{Zinc Fingers and Homeoboxes Protein 1 (ZHX1)}

Quantitative determination of rat zinc fingers (ZHX1) was performed using a commercially available ELISA kit (CUSABIO $^{\odot}$, Biotech Limited, China) according to the manufacturer's instructions.

\section{Thiobarburic acid reactive substances (TBARS) assay}

This assay was performed using a commercially available Kit (QuantiChrom ${ }^{\mathrm{TM}}$, Gentaur Molecular Products, 
Kampenhout, Belgium) according to the manufacturer's instructions.

\section{Serum biochemical analyses}

A clinical biochemical analyzer (Humalyzer 2000, Wiesbaden, Germany) was used to analyze serum samples for total proteins, albumin and liver enzymes ALT, AST and ALP using commercial reagent kits (Human Diagnostics, Wiesbaden, Germany) according to the manufacturer's instructions.

\section{Data analysis}

Value were expressed as mean \pm SEM followed by Oneway Analysis Variance.

\section{RESULTS}

\section{Analysis of tea}

The HPLC analysis effectively separated the tea catechins and caffeine based on their elution profiles. The results show that the elution time of the green tea was as follows; Gallic acid (GA), Epigallocatechin (EGC), Catechin (C), Caffein (CAFF), Epicatechin (EC), Epigallocatechin gallate (EGCG) and Epicatechin gallate (ECG).

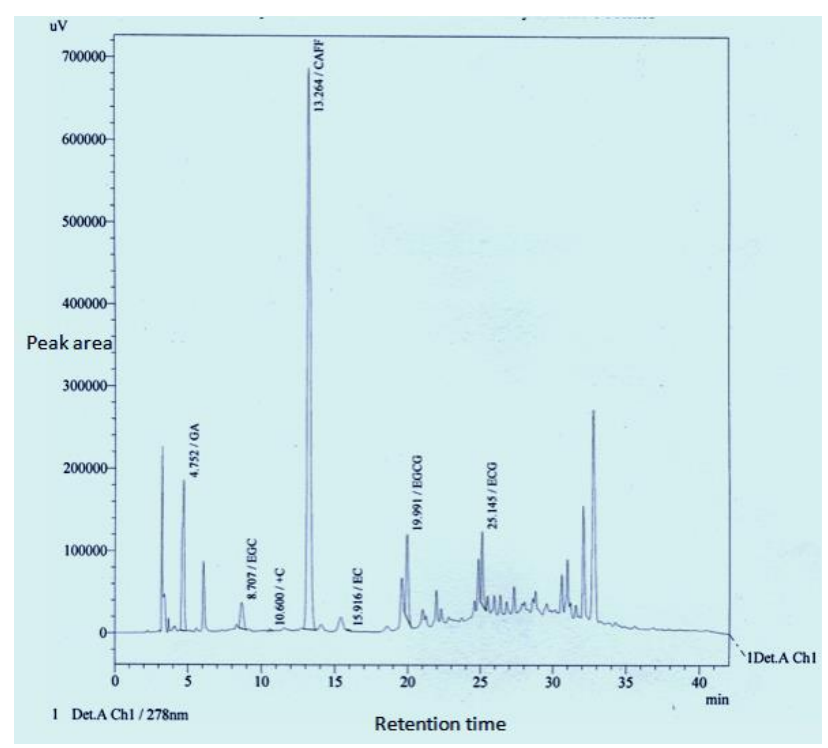

$\mathrm{X}$-axis $=$ Retention time $(\min ) \mathrm{Y}$-axis $=$ Peak area

Figure 1: A chromatogram of Kenyan black tea variety TRFK 6/8 showing catechins elution time.

As shown in Figure 2, the catechins eluted in the following order; Gallic acid (GA), Epigallocatechin (EGC), Catechin (C), Caffein (CAFF), Epicatechin (EC), Epigallocatechin gallate (EGCG) and Epicatechin gallate (ECG).

Table 1: Individual catechin (\%) levels of black and green tea analyzed.

\begin{tabular}{|llllll|}
\hline Sample category (TRFK6/8) & EGCG\% & EGC\% & ECG\% & EC\% & C\% \\
\hline Black & ${ }^{\mathrm{b}} 2.9 \pm 0.258$ & ${ }^{\mathrm{b}} 1.7 \pm 0.175$ & ${ }^{\mathrm{b}} 1.1 \pm 0.291$ & ${ }^{\mathrm{b}} 0.5 \pm 0.161$ & ${ }^{\mathrm{a}} 0.6 \pm 0.399$ \\
\hline Green & ${ }^{\mathrm{a}} 7.8 \pm 0.184$ & ${ }^{\mathrm{a}} 4.3 \pm 0.597$ & ${ }^{\mathrm{a}} 2.9 \pm 0.258$ & ${ }^{\mathrm{a}} 1.5 \pm 0.245$ & ${ }^{\mathrm{a}} 0.4 \pm 0.074$ \\
\hline
\end{tabular}

Means within a column with the same superscript letter(s) are not statistically different at $\mathrm{p}<0.05$

Table 2: Percent total polyphenols (TP), antioxidant capacity (AA), theaflavins (TF) and thearubigins (TR) of black and green tea analyzed.

\begin{tabular}{|lllll|} 
Sample category (TRFK6/8) & TP\% & AA \% & TF\% & TR\% \\
\hline Black & ${ }^{\mathrm{b}} 20.4 \pm 0.34$ & ${ }^{\mathrm{b}} 77.6 \pm 0.83$ & ${ }^{\mathrm{b}} 2.6 \pm 0.04$ & ${ }^{\mathrm{b}} 17.8 \pm 0.184$ \\
\hline Green & ${ }^{\mathrm{a}} 25.0 \pm 0.12$ & ${ }^{\mathrm{a}} 88.7 \pm 0.47$ & ${ }^{\mathrm{a}} 0.1 \pm 0.005$ & ${ }^{\mathrm{a}} 4.9 \pm 0.14$ \\
\hline
\end{tabular}

Means within a column within the same superscript letter(s) are not statistically different at $\mathrm{p}<0.05$

Table 3: Levels of Cadmium and trace elements in tea.

\begin{tabular}{|c|c|c|c|c|c|c|c|c|c|c|}
\hline Sample category & $\begin{array}{l}\text { Cd } \\
(\mathbf{p p b})\end{array}$ & $\begin{array}{l}\mathrm{Mg} \\
(\%)\end{array}$ & $\begin{array}{l}\text { Al } \\
\text { (ppm) }\end{array}$ & $\begin{array}{l}\text { Mn } \\
(\%)\end{array}$ & $\begin{array}{l}K \\
(\%)\end{array}$ & $\begin{array}{l}\mathrm{Cu} \\
(\mathrm{ppm})\end{array}$ & $\begin{array}{l}\text { Fe } \\
(\mathrm{ppm})\end{array}$ & $\mathbf{S}(\%)$ & $\begin{array}{l}\mathrm{Zn} \\
(\mathrm{ppm})\end{array}$ & $\begin{array}{l}\mathrm{Ca} \\
(\%)\end{array}$ \\
\hline Black-tea (TRFK6/8) & 0.63 & 0.55 & 4030 & 0.563 & 1.47 & 285 & 407 & 0.63 & 103 & 1.49 \\
\hline Green tea (TRFK6/8) & 0.61 & 0.52 & 3940 & 0.541 & 1.47 & 285 & 413 & 0.57 & 99.7 & 1.41 \\
\hline
\end{tabular}

There were no significant $(\mathrm{P}>0.05)$ differences in the levels of metals between both types of tea used in this study

Green tea samples had significantly $(\mathrm{P}<0.05)$ higher levels of EGCG, EGC, ECG and EC. There was no significant difference in $\mathrm{C} \%$ between the two tea samples.

The green tea sample had significantly $(\mathrm{P}<0.005)$ higher TP (\%) and AA (\%) than black tea while TF (\%) and TR
$(\%)$ were significantly $(\mathrm{P}<0.005)$ higher in black than in green tea.

Rats that were treated with green tea or black tea registered a significant $(\mathrm{p}<0.0001)$ increase in bwt throughout the experiment (Figure 4). Further, the rats that received $200 \mathrm{mg} / \mathrm{kg}$ body weight of black tea intra gavage dropped 
at week 4 post administrations from $320.88 \pm 22.61 \mathrm{~g}$ to $280.52 \pm 25.26$ and increased sharply at week 5 post administrations from $280.52 \pm 25.26 \mathrm{~g}$ to $327.20 \pm 18.09 \mathrm{~g}$.

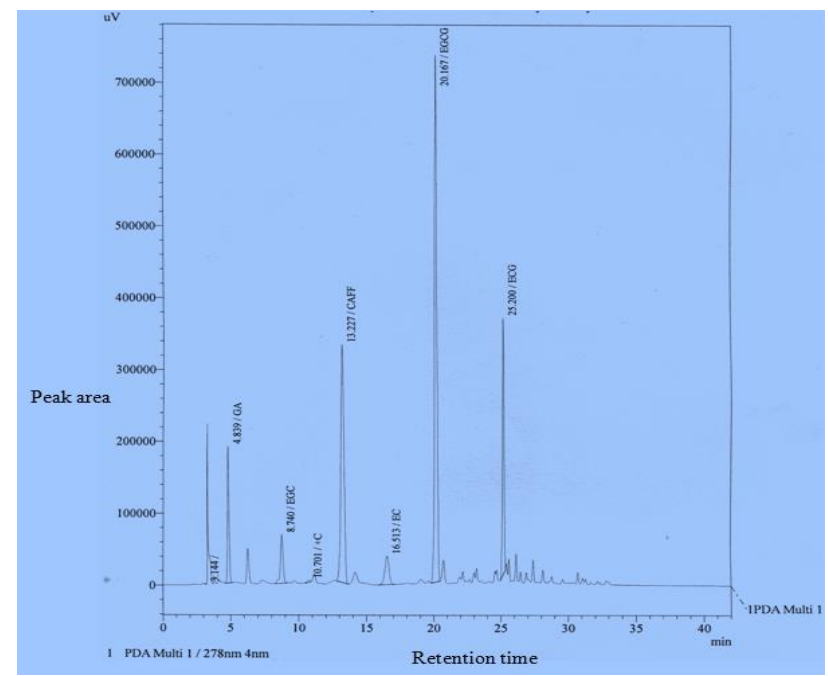

$\mathrm{X}$-axis $=$ Retention time $(\min ) \mathrm{Y}$-axis $=$ Peak area

Figure 2: A chromatogram of Kenyan green tea variety TRFK 6/8 showing catechins elution time.

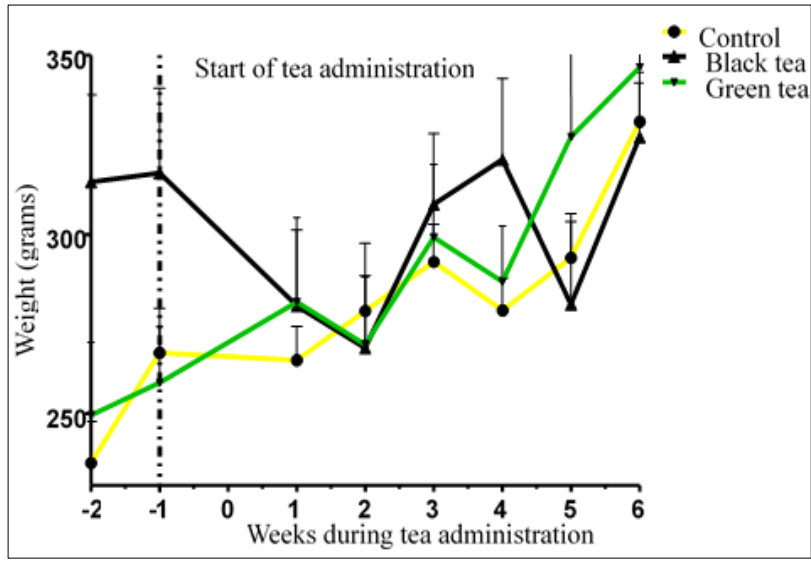

Figure 3: Changes in body weight of rats supplied with either black tea extracts or green tea.

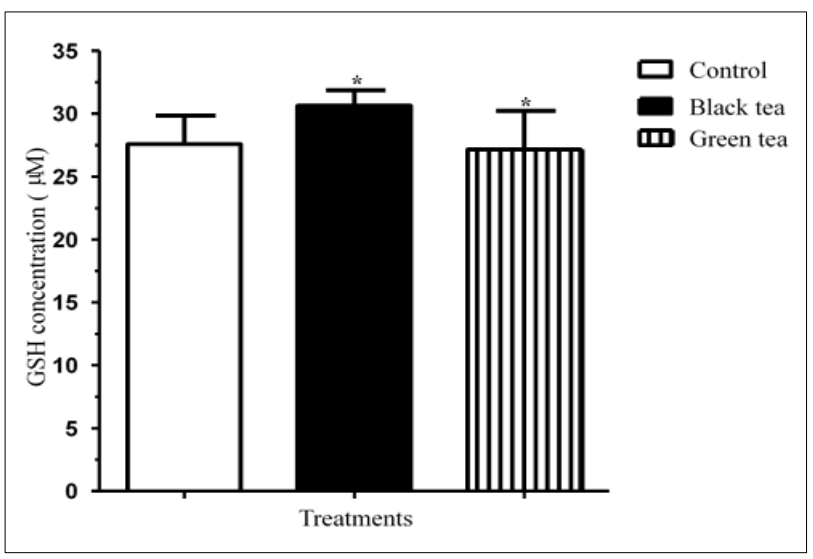

Figure 4: Effect black or green tea on liver GSH levels in rats.

\section{Effects of tea on the liver of rats}

Treatment of rats with tea extracts did not significantly ( $p>0.05)$ affect liver GSH, TBARS, ZHX1 tissue homogenates as shown in Figure 4, 5 and Figure 6.

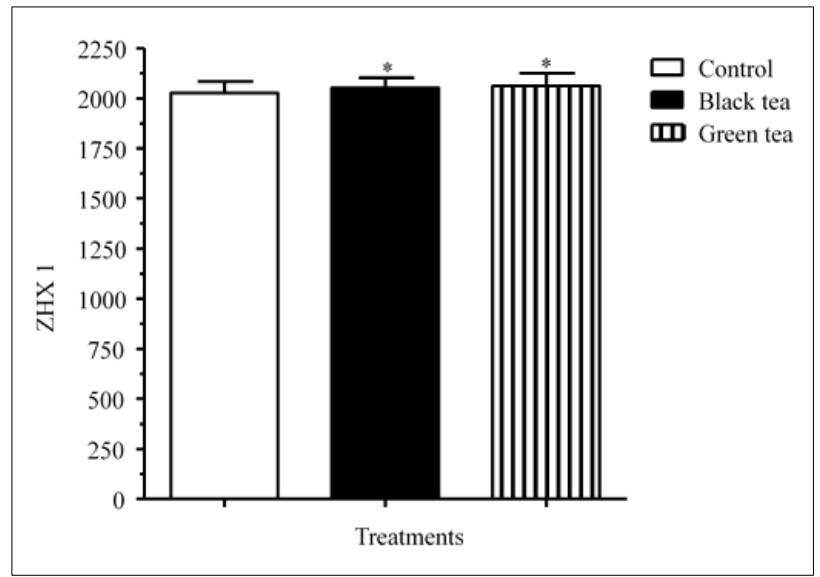

Figure 5: Effect of black or green tea on liver ZHX1 levels in rats.

\section{Glutathione}

There was no significant ( $p>0.05$ ) differences between the various treatment groups. There was also no significant ( $p>0.05$ ) difference between the groups when compared with the control group.

\section{Zinc fingers and homeoboxes I (ZHXI)}

No significant $(p>0.05)$ differences were recorded between the various treatment groups. In addition, there was no significant $(p>0.05)$ difference between the treatment groups when compared with the control group.

\section{Thiobarburic acid assays (TBARS)}

*There was no significant ( $p>0.05$ ) difference in the MDA levels between rats that were supplied with either black tea or green tea when compared to the control animals that were supplied with water only.

\section{Serum Biochemistry tests}

The aminotransferases and alkaline phosphatase assays assessed the integrity of the hepatocytes and the total proteins (TP) and albumin levels evaluated the biosynthetic capacity of the liver.

\section{Alanine aminotransferase $(A L T)$}

There was no significant $(p>0.05)$ difference on serum ALT levels between rats that were supplied with either black tea or green tea when compared to the control rats that were supplied with water only. 


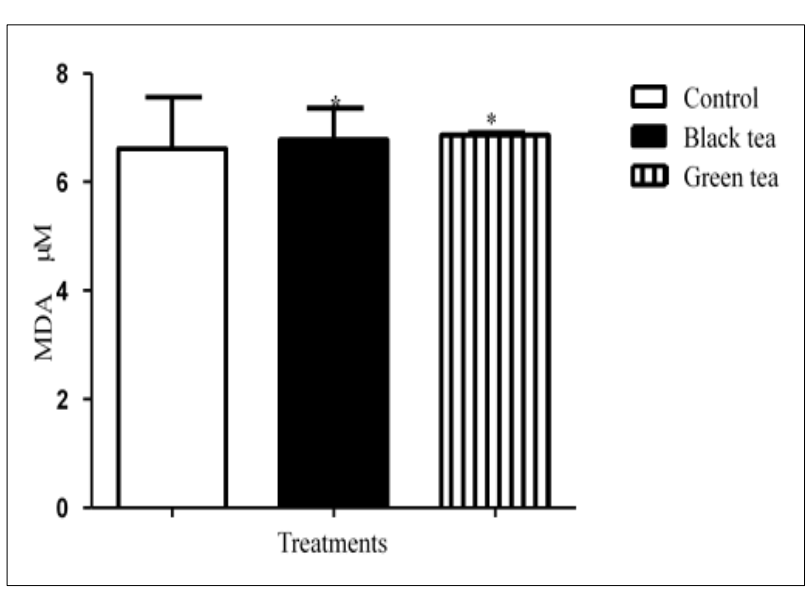

Figure 6: Effect of either black or green tea on liver MDA levels in rats.

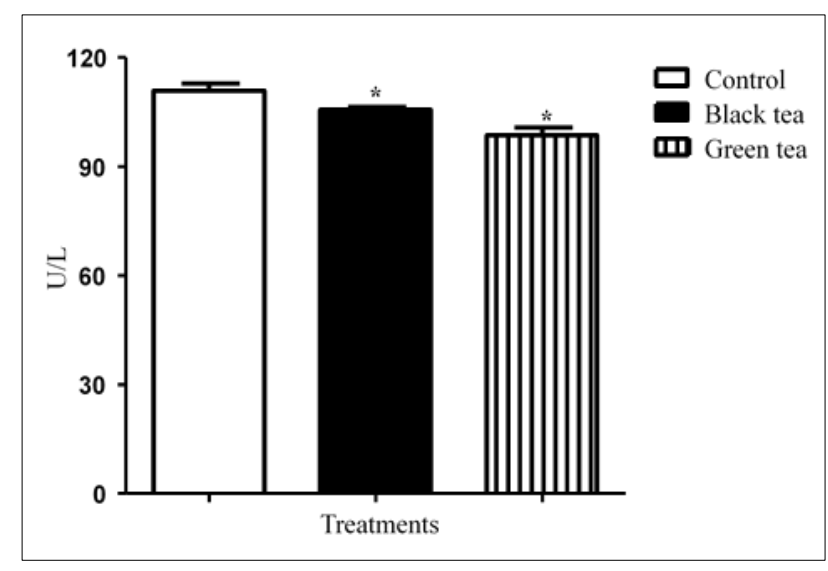

Figure 7: Effect of black or green tea on serum ALT levels in rats.

\section{Aspartate Aminotransferase (AST)}

There was significant $\mathrm{p}<0.0054$ difference on serum AST levels when compared to the control rats that received water only. At the same time there was no significant ( $p>0.05)$ difference between the groups.

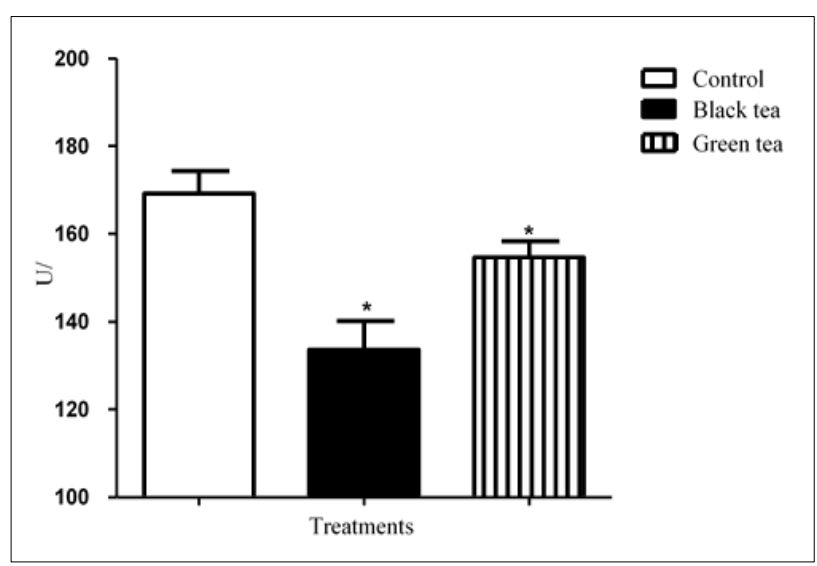

Figure 8: Effect of either black or green tea on serum AST levels in rats.

\section{Alkaline phosphatase}

There was significant $(\mathrm{p}<0.2035)$ differences in the serum ALP levels between rats that were supplied with either black tea or green tea when compared to those that received water only.

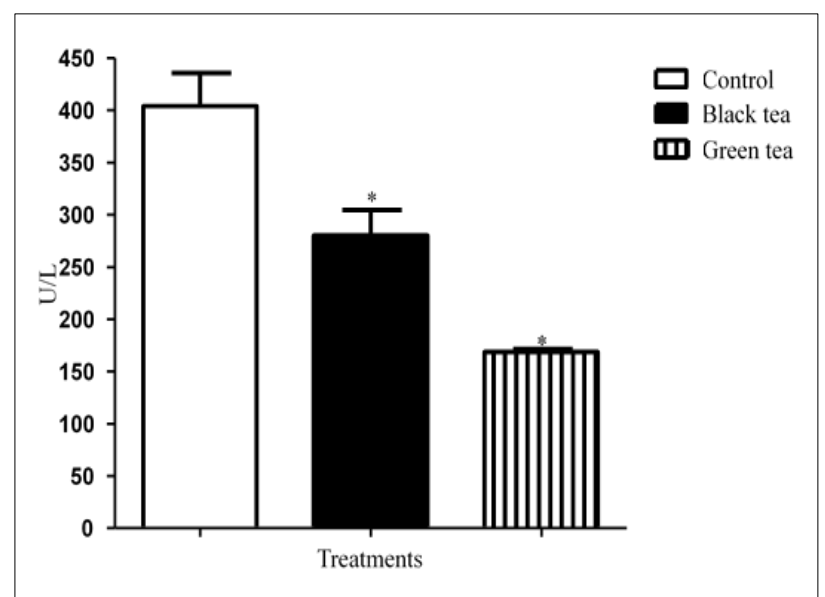

Figure 9: Effect of the chelating antioxidants on serum ALP levels in rats.

\section{Total proteins}

There was no significant $(p>0.05)$ differences were recorded between the various treatment groups. At the same time there was no significant $(p>0.05)$ difference between the groups when compared with the control group.

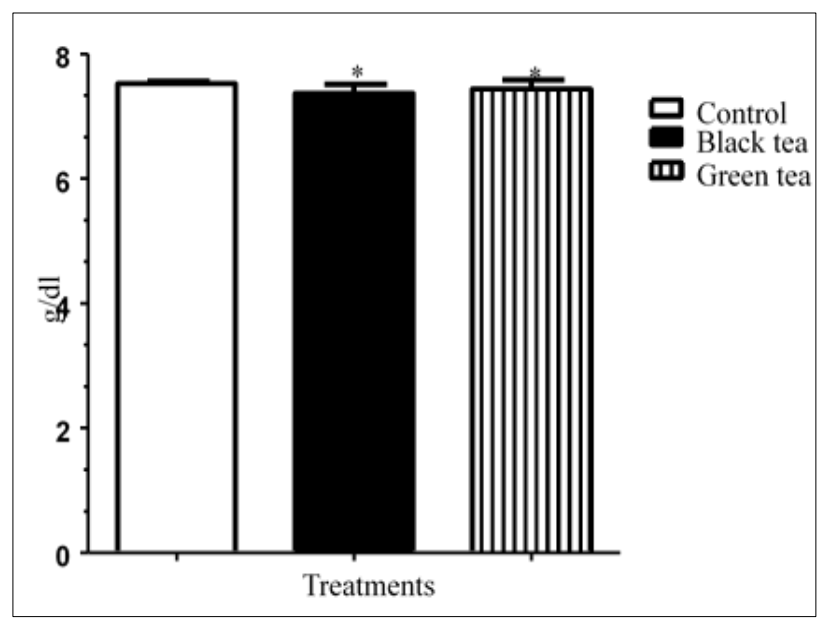

Figure 10: Effect of either black or green tea on total protein levels in rats.

\section{Albumin}

There was no significant $(\mathrm{P}>0.05)$ difference in albumin levels between the tea groups and the control group. 


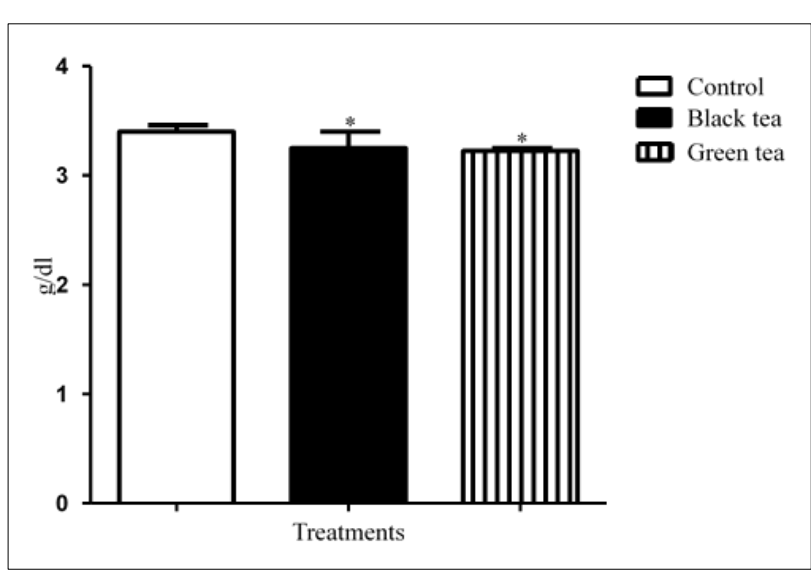

Figure 11: Effect of black or green tea on serum albumin levels in rats.

\section{DISCUSSION}

The levels of total polyphenols, total theaflavins and antioxidant capacity of both aerated and unaerated teas processed from cultivar TFRK 6/8 were determined. The green (unaerated) and the black (aerated) differed significantly in the levels of total polyphenols $(\mathrm{p} \leq 0.05)$. Total polyphenol content of aerated and an aerated tea processed was $20.4 \%$ and $25.0 \%$ respectively. Total polyphenols which are constituents of secondary metabolism in plants remained almost intact in unaerated processed teas, since the enzyme polyphenol oxidase is inactivated by heat during the early stages of processing. ${ }^{16}$ Green tea polyphenols consist of simple and complex compounds, the large majority of which are the flavonoid monomers catechins, catechin gallates and flavonols. ${ }^{17,18}$ While, black tea consists of residual green tea polyphenols such as catechins, flavonols and oxidation products of green tea polyphenols such as theaflavins and thearubigins. ${ }^{18}$

The amount of polyphenols in green tea is higher than that of black teas since the auto-oxidation results to significant conversion of the polyphenols to highly polymerized molecules; thearubigins and theaflavins. ${ }^{19}$

The total catechins levels were statistically different $(\mathrm{p}<0.05)$. Black (aerated) teas had lower catechin levels than the green (non-aerated) teas. Individual catechins varied significantly $(\mathrm{p}<0.05)$ among the teas with EGCG, GC and EGC levels being the highest and $+\mathrm{C}$, ECG and EC being less abundant. These results are in agreement with those of. ${ }^{20}$ This clearly shows that the auto-oxidation step of black tea processing also interfered with the total catechins content of the final product. During the manufacture of black tea, the polyphenol oxidase enzyme catalyzes the oxidation of catechins into quinones by molecular oxygen. ${ }^{21}$ In the aforementioned process, the quinones further condense to form theaflavins, thearubigins, bisflavonols and other complex oligomers. ${ }^{22}$ On the contrary, green tea is manufactured by inactivating the fermentation process by passing the freshly harvested tea leaves in steam or pan firing treatment, leaving catechins almost intact. ${ }^{23}$ These processing methods of tea give forth to preparations with different chemical configurations and different pharmacological properties.

The HPLC catechins profiling revealed that the elution time and the order of elution of individual catechins was as follows; Gallic acid (GA), Epigallocatechin (EGC), Catechin (C), Caffein (CAFF), Epicatechin (EC), Epigallocatechin gallate (EGCG) and Epicatechin gallate (ECG). The highest peaks were recorded for EGCG EGC and ECG respectively, a result that corroborated with earlier studies. ${ }^{19}$ However, alongside the key peaks identified, several minor peaks were also fractionated; indicating that other unidentified catechins existed in the tea extracts (Figure 1 and 2). There was however great similarity in the HPLC chromatographic pattern which indicated the close similarity in catechin profiles in both black and green tea studied. A similar observation was made by. ${ }^{19}$

The levels of theaflavins and thearubigins which are the main products of fermentation increased in black tea when compared to green tea. Black tea recorded $2.19 \%$ and $16.13 \%$ of TFs and TRs, respectively while the levels of TFs and TRs in green tea were $1.46 \%$ and $12.36 \%$, respectively. This is in line with other studies which cited the release of polyphenol oxidase that interacts with phenolic compounds to form theaflavins and thearubigins. ${ }^{19,24}$ The two types of processed tea leaf used in this study contained some amount of metals (Table 3). Aluminum was the most predominant and magnesium was the lowest. The study showed that tea is a good source of manganese, copper and calcium in diet as their levels match the acceptable daily intakes and do not therefore expose the tea user to high levels which can be toxic. The nonessential elements including aluminum, lead and cadmium were in very low concentrations in tea infusions and thus do not pose any risks in terms of toxic metals in diet, with their contents matching permissible levels for toxic metals in food and beverages. These results agree with other studies which suggested that tea grown and marketed in Kenya is potentially rich in dietary source of some essential minerals including $\mathrm{Fe}, \mathrm{Zn}$ and $\mathrm{Cu}$ and had $\mathrm{Fe}, \mathrm{Zn}, \mathrm{Cu}, \mathrm{Pb}$ and $\mathrm{Cd}$ levels well within the international (Maximum Permissible Concentrations) MPC's set for tea. $^{25}$

One of the areas of research on tea that has elicited a lot interest is its antioxidant capacity. ${ }^{17,21,26,27}$ In line with this fact, the antioxidant capability of both green and black teas that were used in this study was determined. Overall, green tea recorded higher percent antioxidant capacity than black tea, that is, $88.7 \%$ and $77.6 \%$, respectively. The high antioxidant capacity of green tea could be related to its high levels of free catechins. Other studies have correlated between high antioxidant activity in tea extracts with high levels of EGCG, EGC and ECG. ${ }^{19,27}$ It has been hypothesized that the most potent antioxidants are catechins that possess a 3'4' and 5'-trihydoxlated 
substitution pattern on the B ring and/or hydroxyl group at the $\mathrm{C}-3$ position of the catechins structure. ${ }^{19}$ This stabilizes the catechins phenoxyl radical through participation in electron delocalization which is a very important phenomenon in anti-radical potential.

Although tea has for a long time been well-thought out as a beverage, current information shows that many people are starting to think of it as a potent medicinal compound that is endowed with numerous health benefits. ${ }^{28}$ This is due to its biological and pharmacological activities that have potential health benefits to humans. ${ }^{29}$ These potential health benefits of tea have been ascribed to their high levels catechins, thearubigins and theaflavins. ${ }^{30}$ However, there is still a paucity of data in Kenya on the biochemical and clinical effects of tea extracts in the liver. It has been shown that tea has the ability to interrupt auto-oxidation and confer protection against deleterious xenobiotic mediated oxidative stress through chelating metal ions, inhibiting formation of free radicals, breaking the autooxidative chain reactions and reducing localized oxygen concentrations. ${ }^{31}$ Perhaps, the chemical potency of tea and its lipophilic nature makes it access peroxy radicals especially in membrane, micellar and emulsion systems. ${ }^{32}$

Results from this study showed that the tea extracts did not have any significant effect on GSH, ZHX1, TBARS, TP, ALB and ALT. The tea however significantly reduced the activities of serum aminotransferase AST and ALP when compared to the control group. This effect would largely be attributed to the antioxidant capacity of the tea extracts and has no toxicological significance. ${ }^{33}$ In this research, the maintenance of the liver enzymes to levels comparable with the controls shows that the tea extracts did not injure the cells thus maintaining the enzymes inside the cells. Studies have shown that tea protects the liver against free radical injuries and may act as an electron donor inside cells and thus improve liver necrosis and decreases serum transaminases. ${ }^{34}$ This is a clear indication that the tea extracts used in this study were none toxic and were well tolerated by the rats. Other studies have documented that tea is rapidly absorbed and distributed into the mucous membrane of the small intestines, the liver and most importantly it crosses the blood brain barrier. ${ }^{35}$

In this study, tea caused minimum body weight gain with few fluctuations throughout the experimental period in the rats used. This body weight gain was relative to the initial body weight of the rats. Similar observations were made by. ${ }^{36}$ who inferred that, body weight gain or loss is dose dependent.

It is obvious from the current study that tea safeguards the liver by maintaining and improving the structural and cellular membrane integrity with eventual alleviation of the oxidative changes as well as the biochemical perturbations. This may be encouraging as tea may be used a cushion for prolonged therapeutic option against major xenobiotics and pro oxidants such as superoxide, hydroxyl, singlet oxygen and nitrites that cause a battery of disease conditions. ${ }^{37}$ While a number of mechanisms continue to be put forward for the valuable effects of tea in different models of protracted disease conditions, the chelating ability, radical scavenging and antioxidant properties of tea polyphenols appear to be the most repeatedly quoted. Subsequently tea enhances antioxidant enzymes that suppress carcinogen induced ROS and DNA damage because it is a good dual antioxidant with low mammalian toxicity and ability to penetrate membranes and even pass through the blood-brain barrier (BBB). Additionally, tea is easily administered and highly soluble in water forming non-toxic complexes. ${ }^{38,39}$

\section{CONCLUSION}

In conclusion, tea can be considered as an absolute antioxidant that can be used to deal with oxidative stress due to pro-oxidants. This is due to the fact that, tea neither caused adverse effects nor impaired liver function of the animals used in the current study. These results show that consumption of either black or green tea prevented cell damage of the liver, resulting to either maintaining the same levels as controls of serum liver enzymes or decreased serum concentrations of aspartate aminotransferase (AST) and alanine aminotransferase (ALT) as well as that of alkaline phosphatase (ALP).

\section{Recommendations}

Since polyphenols in tea are nontoxic, they can be extracted and marketed as pharmacological compounds with immense health properties thus diversifying the uses of tea. The possible mechanisms of protection by tea polyphenols against oxidative stress has been reported in this study, however, further research is needed to determine the clinical mechanisms of this action in more details, and to explore other beneficial effects that these polyphenols may have, before they can be adopted as pharmacological agents. The use tea could be the best inexpensive choice for protecting man against many disease conditions. This study highly recommends the employment of next generation sequencing platforms to explore the would-be health properties of tea polyphenols.

\section{ACKNOWLEDGEMENTS}

This study was supported by the Tea Research Institute of Kenya.

\section{Funding: No funding sources Conflict of interest: None declared \\ Ethical approval: The study was approved by the Institutional Ethics Committee}

\section{REFERENCES}

1. Cabrera C, Artacho R, Gimenez R. Beneficial effects of green tea: A review. J Amer Colle Nutriti. 2006;25:79-99. 
2. Kodama DH, Gonçalves SA, Lajolo FM, Genovese IM. Flavonoids, total phenolics and antioxidant capacity: comparison between commercial green tea preparations. Food Science and Technology. 2010;30:1077-82.

3. Ramadan G, Nadia ME, Eman A, El-Ghffar A. Modulatory effects of black versus green tea aqueous extract on hyperglycaemia, hyperlipidaemia and liver dysfunction in diabetic and obese rat models. Brit $\mathbf{J}$ Nutritio. 2009;102:1611-9.

4. Yang G, Liao J, Kim K, Yurkow EJ, Yang CS. Inhibition of growth and induction of apoptosis in human cancer cell lines by tea polyphenols. Carcinogenesis. 1998;19:611-6.

5. Katiyar SK, Mukhtar H. Tea consumption and cancer. World Review of Nutrition and Diet. 1996;79:154-84.

6. Kumamoto M, Sonda T, Nagayama K, Tabata M. Effects of $\mathrm{pH}$ and metal ions on antioxidant activities of catechins. Bioscience Biotechnology and Biochemistry. 2001;65:126-32.

7. Kerio LC, Wachira FN, Wanyoko JK, Rotich MK. Total Polyphenols, Catechin Profiles and Antioxidant Activity of Tea Products Food Chemistry. 2012;136:1405-13.

8. Pourmorad F, Husseinimehr SJ, Shahabimajd N. Antioxidant, phenol and flavanoid contents of some selected Iranian medicinal plants. Afr J Biotechnol. 2006;5:1142-5.

9. Hilton PJ, Palmer-Jones R. Relationship between the flavanol composition of fresh tea shoots and theaflavin content of manufactured tea. J Sci Food and Agricult. 1973;24:813-8.

10. Roberts EAH, Smith RF. Spectrophotometric measurements of theaflavins and thearubigins in black tea liquors in assessments of quality in teas. Analyst. 1961;86:94-8.

11. Brand-Williams W, Cuvellier ME, Berset C. Use of free radical method to evaluate antioxidant activity. Lebensm Wiss Technology. 1995;28:25-30.

12. Ambadekar SR, Parab S, Bachankar A. Determination of cadmium, copper, nickel, lead in some tea samples in India. International $\mathbf{J}$ Res in Pharmace Biome Scienc. 2012;3:943-6.

13. Rahman I, Kode A, Biswas SK. Assay for quantitative determination of glutathione and glutathione disulfide levels using enzymatic recycling method Nature Protocols. 2007;1:3159-65.

14. Rashid K, Wachira FN, Nyabuga JN, Wanyonyi B, Murilla G, Isaac AO. Kenyan purple tea anthocyanins ability to cross the blood brain barrier and reinforce brain antioxidant capacity in mice Nutritional Neuroscience. 2014;17:178-85.

15. Ingrid P. Tea Flavonols; An overview. Victor Preedy (EDS). Tea in health and disease prevention. Elsevier, London; 2012:73-79.

16. Jenny T. Mao MD. White tea: The plants, Processing, Manufacturing and potential health benefits. In: Victor Preedy (EDS), Tea in health and disease prevention. Elsevier, London; 2012:3-16.
17. Shitandi A, Ngure FM, Mahungu SM. Tea Processing and its Impact on Catechins, Theaflavin and Thearubigin Formation. Victor Preedy (Eds). Tea in Health and Disease Prevention. Elsevier, London; 2012:193-206.

18. Karori SM, Wachira F, Ngure RM, Mireji PO. Polyphenolic composition and antioxidant activity of Kenyan Tea cultivars. J Pharmaco and Phytochemi. 2014;3:105-16.

19. Karori SM, Wachira F, Wanyoko JK, Ngure RM. Antioxidant capacity of different types of tea products. Afric J Biotechnol. 2007;6:2287-96.

20. Selena A, Steep JR. Green tea: The processing, manufacturing and production. Victor Preedy (EDS). Tea in health and disease prevention. Elsevier, London; 2012:19-32.

21. Riemersma RA, Rice-Evans CA, Tyrrell RM, Clifford MN, Lean ME. Tea Flavonoids and Cardiovascular Health QJM. An Int J Medi. 2001;94:277-82.

22. Sabu MC, Smitha K, Kuttan R. Anti-diabetic activity of green tea polyphenols and their role in reducing oxidative stress in experimental diabetes. J Ethnopharmacol. 2002;83:109-16.

23. Moseti KO, Kinyanjui T, Wanyoko JK, Kurgat JK, Too JC, Omondi KG, et al. Fe, $\mathrm{Zn}, \mathrm{Cu}, \mathrm{Pb}$ and $\mathrm{Cd}$ in Tea Grown and Marketed in Kenya; A Quantitative Assessment Int J Environ Protec. 2013;3:24-30.

24. Mandel S, Youndin MB. Catechin polyphenols: neurodegeneration and neuroprotection in neurodegenerative diseases. Free Radical Biology and Medicine. 2004;37:304-17.

25. Kopjar M, Tadi M, Piliota V. Phenol content and antioxidant activity of green, yellow and black tea leaves Chemical and Biological Technologies in Agriculture. 2015;2:1-6.

26. Gramza A, Khokhar S, Yoko S, Swiglo GA, Hes M, Korczak J. Antioxidant activity of tea extracts in lipids and their correlation with polyphenolic content. Europ J Sci and Technol. 2006;108:351-62.

27. Xiang LiP, Wang A, Ye JH, Zheng XQ, Polito CA, Lu JL, et al. Suppressive Effects of Tea Catechins on Breast Cancer Nutrients. 2016;8:458.

28. Mandel S, Amit T, Reznichenko L, Weinreb O, Youdim MB. Green tea catechins as brain-permeable, natural iron chelatorsantioxidants for the treatment of neurodegenerative disorders. Molecular Nutrition and Food Research. 2006;50:229-34.

29. Rietveld A, Wiseman S. Antioxidant effects of tea: evidence from human clinical trials. $\mathrm{J}$ Nutriti. 2003; $133: 3285$ S-92S.

30. Brewer MS. Natural Antioxidants: Sources, Compounds, Mechanisms of Action, and Potential Applications. Comprehensive reviews in food science. 2011;10:1541-4337.

31. Wanatabe Y, Nakanashi H, Goto N, Otsuka K, Kimura $\mathrm{T}$, Adachi S. Antioxidative properties of ascorbic acid and acyl ascorbates in ML/W emulsion. Journal of the American Oil Chemists' Society. 2010;85:1475-80. 
32. Sung H, Nah J, Chun S, Park H, Yang SE, Min WK. In vivo antioxidant effect of green tea. European Journal of Clinical Nutrition. 2000;54:527-9.

33. Khorsandi LS, Javadnia F, Orazizadeh M, Abdolahi M. [Effect of green tea (Camellia sinensis L.) extract on acetaminophen induced acute hepatotoxicity in mice] Persian. Iran J Medici and Aromat Plan. 2010;26(1):22-9.

34. Rashid K, Wachira FN, Nyabuga JN, Wanyonyi B, Murilla G, Isaac AO. Kenyan purple tea anthocyanins ability to cross the blood brain barrier and reinforce brain antioxidant capacity in mice Nutritional Neuroscience. 2014;17:178-85.

35. Kao Y, Hiipakka RA, Liao S. Modulation of obesity by a green tea catechin The Amer J Clin Nutriti. 2000;72:1232-3.

36. Flora SJS, Mittal M, Mehta A. Heavy metal induced oxidative stress and its possible reversal by chelation therapy. Ind J Med Resear. 2008;128:501-23.
37. Flora SJS, Pachauri V. Chelation in metal intoxication. International Journal of Environmental Research and Public Health. 2010;7:2745-88.

38. Weinreb O, Tamar A, Silvia M, Moussa BHY. Neuroprotective molecular mechanisms of (2)epigallocatechin- 3-gallate: a reflective outcome of its antioxidant, iron chelating and neuritogenic properties. Genes Nutrition. 2009;4:283-96.

Cite this article as: Areba GO, Khalid R, Nderitu NS, Thuo JK, Okongo MK, Mbuthia KS, et al. Antioxidant activity and effects of Kenyan Tea (Camellia sinensis) on the liver function and serum biochemistry in male Wistar rats. Int J Basic Clin Pharmacol 2018;7:1471-9. 